\title{
Ultrasonic Effects on Microstructure Evolution and Mechanical Properties of AZ80 Magnesium Alloy
}

\author{
Xue Hansong ${ }^{1,2}, \quad$ Li Di $^{1}, \quad$ Yang Gang ${ }^{1}, \quad$ Zhang Dingfei ${ }^{1,2}$ \\ ${ }^{1}$ College of Material Science and Engineering, Chongqing University, Chongqing 400044, China; ${ }^{2}$ National Engineering Research Center for \\ Magnesium Alloys, Chongqing 400044, China
}

\begin{abstract}
Ultrasonic effects on the microstructure evolution and the mechanical properties of AZ80 alloy were investigated. The results indicate that in the case of the ultrasonic melt treatment, the primary $\alpha$-Mg phases is transformed from coarse dendrites to nearly fine equiaxed grains, and the $\beta-\mathrm{Mg}_{17} \mathrm{Al}_{12}$ phase at $\alpha-\mathrm{Mg}$ boundaries is refined and becomes discontinuous. Besides, the tensile properties of AZ80 alloy are apparently improved after ultrasonic melt treatment, in which $0.2 \%$ tensile yield strength, ultimate tensile strength and elongation are improved from $87 \mathrm{MPa}, 118 \mathrm{MPa}$ and $2.1 \%$ to $107 \mathrm{MPa}, 170 \mathrm{MPa}$ and 5.4\%, respectively.
\end{abstract}

Key words: AZ80 magnesium alloy; ultrasonic treatment; microstructure; mechanical property

In order to satisfy the lightweight requirement in aeronautical and automobile industries, as the lightest construction materials, magnesium alloys are widely used due to their high specific strength, excellent electromagnetic features, superior castability and easy recovery ${ }^{[1-4]}$. Mg-Al system alloys are the most commonly used commercial magnesium alloys. However, the application of this series of magnesium alloys is still restricted by their lower absolute strength and elongation compared to other construction materials. The primary problem is that the grains tend to grow into coarse dendrites because of their large freezing intervals, and a network of eutectic $\beta-\mathrm{Mg}_{17} \mathrm{~A} 1_{12}$ phase existing at grain boundaries is very detrimental to their mechanical properties ${ }^{[5]}$. The conventional method for microstructure modification is to add chemical elements. However, it is not always possible to find a suitable inoculant for a given kind of alloys, such as Al containing magnesium alloys ${ }^{[6]}$. Therefore, physical field of microstructure refinement is desired.

Ultrasonic treatment is an effective physical method for modifying the microstructure of low-melting alloy ${ }^{[7]}$. Nowadays, many researches have been done to investigate the effects of ultrasonic melt treatment on the microstructure and the mechanical properties of light alloy. For example, $\mathrm{Puga}^{[8]}$ reported the effects of ultrasonic treatment during solidification on the microstructure and mechanical properties of $\mathrm{AlSi}_{9} \mathrm{Cu}_{3}$ alloy. Zhang investigated the effects of high-energy ultrasonic melt treatment on the microstructure evolution and mechanical properties of A356 alloy. Patel ${ }^{[10]}$ studied the microstructure modification of AS41 alloy after ultrasonic melt treatment. These researches indicated that ultrasonic melt treatment can modify the microstructure and improve the mechanical properties of the alloys. However, to date, few systematic researches about the effects of ultrasonic melt treatment on AZ80 alloy have been reported, which is the representative of $\mathrm{Mg}-\mathrm{Al}-\mathrm{Zn}$ system alloys. Accordingly, in the present study, ultrasonic effects on microstructure evolution and the mechanical properties of AZ80 alloy were investigated.

\section{Experiment}

The materials used in the experiment were AZ80 magnesium ingots, with nominal composition (wt\%) of $\mathrm{Al}$ 8.22, Zn 0.53, Mn 0.21, Fe 0.001, and Mg balance. Fig.1

$\overline{\text { Received date: June } 14,2015}$

Foundation item: the National Great Theoretic Research Project (2013CB632200); Sharing Fund of Chongqing University's Large-scale Equipment (2013063009) Corresponding author: Xue Hansong, Ph. D., Associate Professor, School of Materials Science and Engineering, Chongqing University, Chongqing 400044, P. R. China, Tel: 0086-23-65111212, E-mail: hsxue@sohu.com 
shows the schematic diagram of the experimental device. It mainly consisted of an ultrasonic generator system with the fixed frequency of $20 \mathrm{kHz}$ and maximum power of $1 \mathrm{~kW}$, a transducer with the size of $30 \mathrm{~mm}$ in diameter, a protection gas system, an electrical resistance furnace and a stainless steel crucible. The equilibrium liquidus temperature and solidus temperature of AZ80 alloy were about 609 and $528{ }^{\circ} \mathrm{C}^{[11]}$, respectively, so the temperature for ultrasonic melt treatment was chosen from $650{ }^{\circ} \mathrm{C}$ to $570{ }^{\circ} \mathrm{C}$. In the experiment, smelting about $0.75 \mathrm{~kg}$ of the alloy was carried out in a stainless steel crucible protected by $\mathrm{CO}_{2}+0.5 \% \mathrm{SF}_{6}$ mixed gas (volume fraction). The alloy was first heated to $720{ }^{\circ} \mathrm{C}$ and maintained for $15 \mathrm{~min}$ at this temperature in order to get full homogenization, then stopped heating the melt. When the melt temperature was reduced to $650{ }^{\circ} \mathrm{C}$, the ultrasonic horn set as $600 \mathrm{~W}$, preheated at $650{ }^{\circ} \mathrm{C}$, was immersed into the melt at a depth of about $20 \mathrm{~mm}$ for ultrasonic treatment. After the melt was cooled down to $570{ }^{\circ} \mathrm{C}$, the ultrasonic horn was removed quickly. Then the crucible was taken out from the electrical resistance furnace, and the melt was cooled to room temperature. In addition, the comparison sample was also prepared under the same conditions but without ultrasonic melt treatment.

The cast specimens were sectioned, ground, mechanically polished and etched in a solution consisting of $35 \mathrm{~mL}$ ethanol, $35 \mathrm{~mL}$ distilled water, $3 \mathrm{~g}$ picric and $2.5 \mathrm{~mL}$ acetic acid. The microstructure observation of the specimens was conducted on an optical metallographic microscope and a scanning electron microscope (SEM, TESCAN VEGA II LMU) equipped with the energy dispersive X-ray spectrometer (EDS, Oxford Inca). The tensile tests were performed at a constant strain rate of $3 \mathrm{~mm} / \mathrm{min}$ on an electronic universal testing machine (Sans CMT 5105) at room temperature.

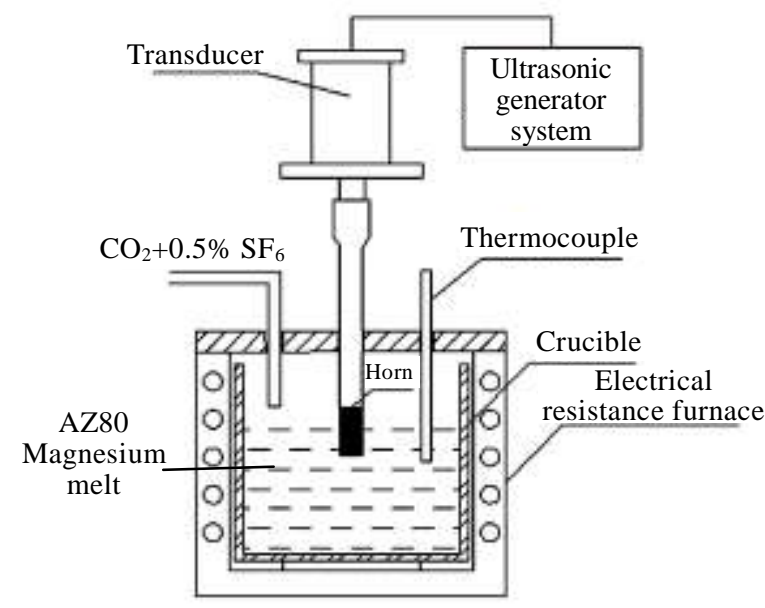

Fig.1 Schematic diagram of the experimental device for ultrasonic melt treatment

\section{Results and Discussion}

\subsection{Microstructure}

Fig.2 shows the microstructures of the experimental alloys with and without ultrasonic melt treatment. As shown in Fig.2a, upon no ultrasonic melt treatment, the primary $\alpha-\mathrm{Mg}$ phase of the alloy exhibits a coarse dendritic structure, which is proved to be a dendrite growth mode. However, when the ultrasonic treatment is introduced into the melt, the alloy exhibits nearly fine equiaxial grains of the primary of $\alpha$-Mg phase, as shown in Fig. $2 \mathrm{~b}$.

Previous studies showed that ultrasonic cavitation may occur when the ultrasonic was introduced into the liquid medium $^{[12,13]}$. According to the references, upon using ultrasonic treatment, the melt is subjected to a local tension stress and further pulled cracks, and the cavitation bubbles are formed. Then, the cavitation bubbles continue to expand until burst, thus creating high pressure pulses in the melt. Under the action of high pressure pulses, the dendrites were fragmentized and subsequently spread into the melt to grow as new grains. Furthermore, the collapse of cavitation bubbles inducing high speed flow in the melt would help to decrease the solute enrichment at the solidification front. Therefore, the influence of constituent supercooling is reduced, and $\alpha-\mathrm{Mg}$ grains are enabled to grow up consistently in all directions to form nearly equiaxial structure.

Fig. 3 shows the SEM images of the experimental alloys with and without ultrasonic melt treatment. It can be observed in Fig.3a that upon no ultrasonic melt treatment, a lot of coarse reticular $\beta-\mathrm{Mg}_{17} \mathrm{Al}_{12}$ phase is white and

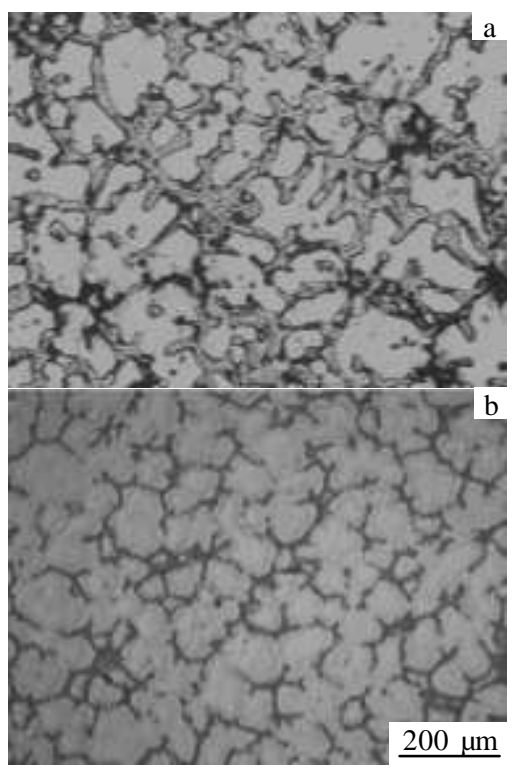

Fig.2 Optical micrographs of AZ80 alloy without (a) and with (b) ultrasonic melt treatment 


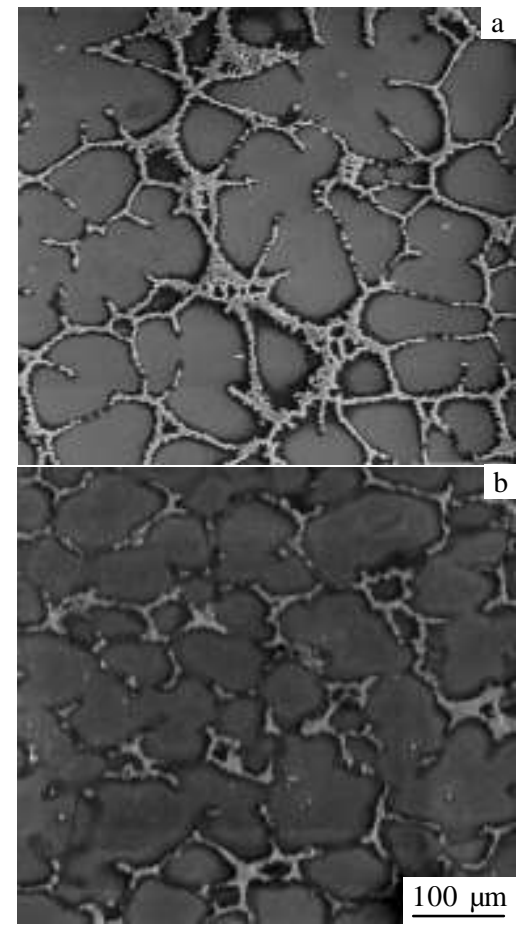

Fig.3 SEM images of AZ80 alloy without (a) and with (b) ultrasonic melt treatment

distributed at $\alpha-\mathrm{Mg}$ boundaries. However, in the case of the ultrasonic melt treatment, it can be seen that the $\beta$ - $\mathrm{Mg}_{17} \mathrm{Al}_{12}$ phase is broken into small pieces and becomes discontinuous, as shown in Fig.3b. Besides, the amount of $\beta$ - $\mathrm{Mg}_{17} \mathrm{Al}_{12}$ phase at $\alpha-\mathrm{Mg}$ boundaries is reduced after ultrasonic treatment, and it can be inferred that more aluminum elements dissolve into $\alpha$-Mg matrix.

The $\beta-\mathrm{Mg}_{17} \mathrm{Al}_{12}$ phase can be fragmented under the impact force generated by collapsed bubbles. Furthermore, the amount of aluminum element dissolving into $\alpha-\mathrm{Mg}$ matrix increases after ultrasonic treatment, which suppresses the formation of $\beta-\mathrm{Mg}_{17} \mathrm{Al}_{12}$ phase, and the reasons will be discussed in the following section. Therefore, the $\beta-\mathrm{Mg}_{17} \mathrm{Al}_{12}$ phase becomes discontinuous.

SEM and EDS were carried out to investigate the distribution of aluminum elements in the experimental alloys. Fig. 4 shows the EDS mapping analyses of aluminum element. It can be seen that the amount of aluminum elements at boundaries is relatively higher than that in the matrix. However, after ultrasonic melt treatment, the boundary segregation of aluminum element is decreased, and more aluminum element dissolves into $\alpha$-Mg matrix, as shown in Fig.4b.

The high speed flow in the melt induced by ultrasonic cavitation can dislodge the aluminum element at the solidification front and disperse it uniformly in the melt.

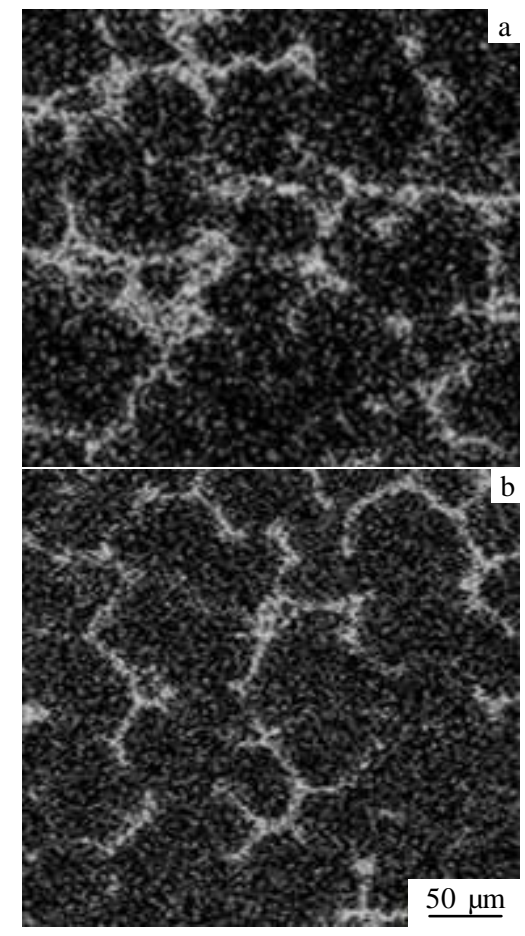

Fig.4 EDS mapping analyses of aluminum elements of AZ80 alloy without (a) and with (b) ultrasonic melt treatment

Furthermore, previous studies showed that ultrasonic treatment in melt could reduce the time of solidification ${ }^{[14]}$. Therefore, the aluminum element has less time to stay in two-phase region and most of it has to dissolve into $\alpha-\mathrm{Mg}$ matrix. In addition, the high localized undercooling induced by ultrasonic cavitation will lead to increase of the movement rate of solidification interface ${ }^{[15]}$, which also contributes to the dissolving of aluminum element into $\alpha-\mathrm{Mg}$ matrix.

\subsection{Mechanical properties}

The tensile tests at room temperature were carried out to investigate the ultrasonic effects on the tensile properties of AZ80 alloy. Fig.5a shows the engineering stress-strain curves of AZ80 alloy with and without ultrasonic melt treatment. Fig. 5b shows the $0.2 \%$ tensile yield strength (YS), ultimate tensile strength (UTS) and fracture elongation of these alloys. As depicted in the figure, the room temperature tensile properties of the alloy are significantly improved after ultrasonic melt treatment, in which the YS, UTS and fracture elongation are improved from $87 \mathrm{MPa}, 118 \mathrm{MPa}$ and $2.1 \%$ to $107 \mathrm{MPa}, 170 \mathrm{MPa}$ and $5.4 \%$, respectively.

The improvement of strength and ductility of the alloy is mainly attributed to three aspects: (1) an nearly equiaxial microstructure is achieved after ultrasonic melt treatment, obviously resulting in the enhanced strength and plasticity; 

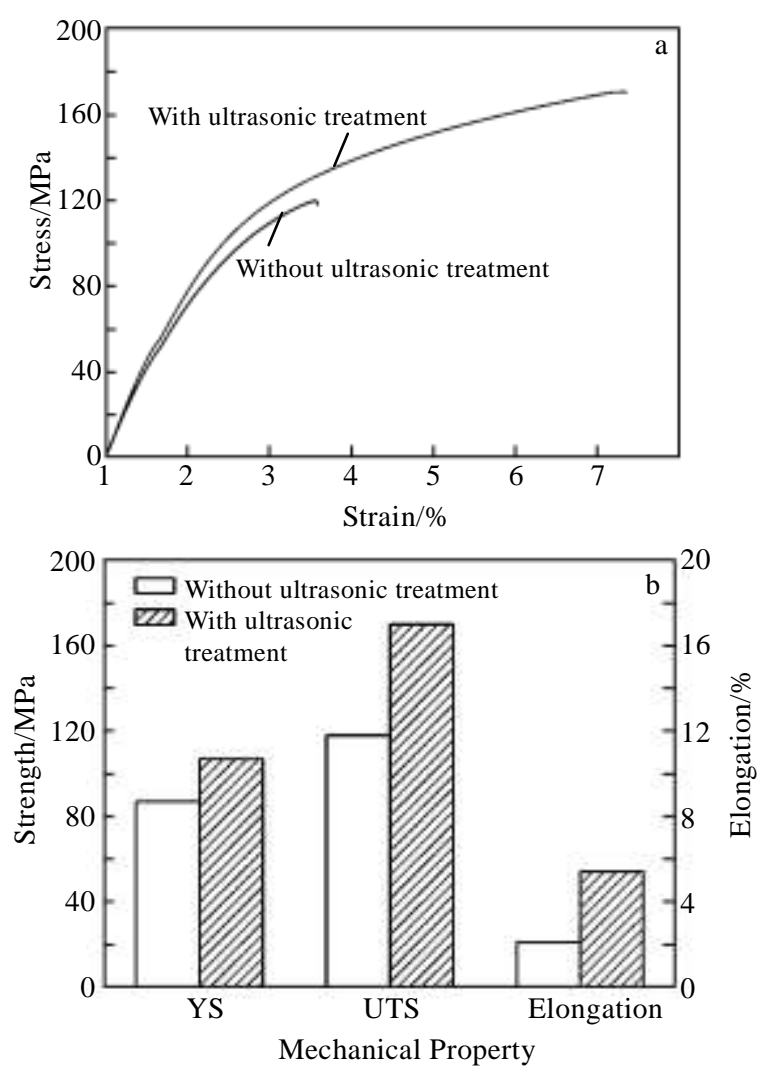

Fig.5 Room temperature tensile properties of AZ80 alloy with and without ultrasonic treatment: (a) engineering stress-strain curves and (b) YS, UTS and elongation

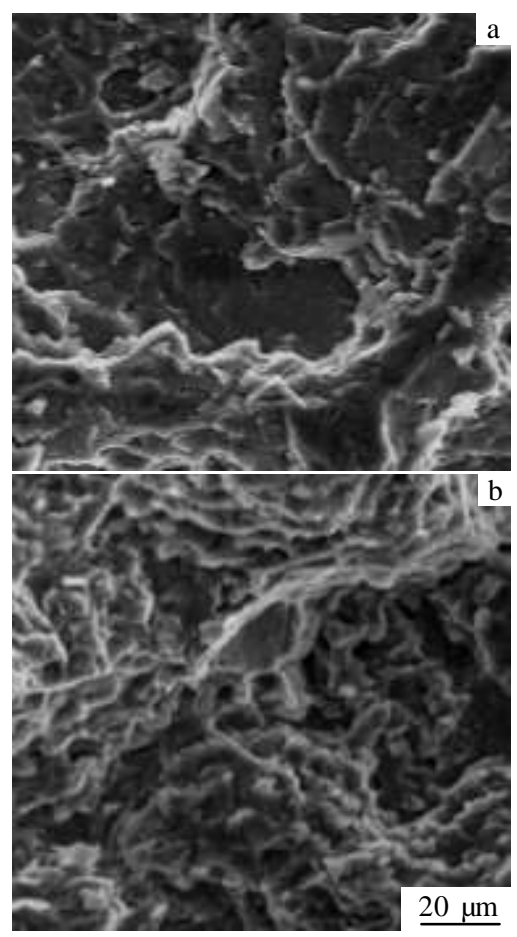

Fig.6 SEM fractographs of AZ80 alloy at room temperature without (a) and with (b) ultrasonic melt treatment
(2) the continuous coarse $\beta-\mathrm{Mg}_{17} \mathrm{Al}_{12}$ phase at $\alpha-\mathrm{Mg}$ boundaries is refined and becomes discontinuous after ultrasonic melt treatment, which can serve as stronger dispersion strengthening. The fine dispersed $\beta-\mathrm{Mg}_{17} \mathrm{Al}_{12}$ phases has little constraint on $\alpha-\mathrm{Mg}$ matrix, which is beneficial to the enhanced plasticity of alloy; (3) the increase of aluminum element dissolving into $\alpha-\mathrm{Mg}$ matrix can enhance the solute strengthening.

Fig.6 shows SEM fractographs at room temperature of AZ80 alloy with and without ultrasonic treatment. It can be seen that both the tensile fracture surfaces mainly consist of many cleavage planes, obvious river patterns and some fine scale dimples, indicating that the fracture behaviors of AZ80 alloy with and without ultrasonic treatment are similar, with the main fracture characteristic of quasi-cleavage. However, upon ultrasonic melt treatment, the tensile fracture surface of AZ80 alloy exhibits more fine scale dimples, as shown in Fig.6b, indicating AZ80 alloy with ultrasonic treatment alloy has relatively high plasticity. Therefore, it can be concluded that the ultrasonic melt treatment does not evidently change the fracture mode, but it will lead to the increase of plasticity of AZ80 alloy.

\section{Conclusions}

1) The microstructure of AZ80 magnesium alloy is remarkably improved after ultrasonic melt treatment. The primary $\alpha-\mathrm{Mg}$ phase is transformed from coarse dendrites to fine equiaxed grains, and the continuous brittle $\beta-\mathrm{Mg}_{17} \mathrm{Al}_{12}$ phase at $\alpha-\mathrm{Mg}$ boundaries is refined and becomes discontinuous.

2) Ultrasonic treatment decreases the segregation of aluminum element at the grain boundaries, and more aluminum element dissolves into $\alpha$-Mg matrix.

3) The tensile properties of AZ80 alloy with ultrasonic treatment are significantly improved compared to those of the untreated alloy, which is mainly related to the nearly equiaxed microstructure and the dispersed $\beta-\mathrm{Mg}_{17} \mathrm{Al}_{12}$ phase at the grain boundaries.

\section{References}

1 Kumar A, Adharapurapu R R, Wayne Jones J et al. Scripta Materialia [J], 2011, 64: 65

2 Manuel M, Louis G H, Ravi V et al. Materials Science and Engineering $A[\mathrm{~J}], 2006,418: 341$

3 Huang C J, Cheng C M, Chou C P. Materials and Manufacturing Processes[J], 2011, 26: 1179

4 Peng X D, Li J C, Xie S Y et al. Rare Metal Materials and Engineering [J], 2013, 42(12): 2421 (in Chinese)

5 Li J Y, Xie J X, Jin J B et al. Transactions of Nonferrous Metals Society of China[J], 2012, 22: 1028

6 StJohn D H, Qian M, Easton M A et al. Metallurgical and Matertials Transactions A[J], 2005, 36: 1669

7 Eskin G L. Ultrasonic Treatment of Light Alloy Melts[M]. 
Amsterdam: Gordon and Breach Science Publishers, 1998: 1

8 Puga H, Costa S, Barbosa J et al. Journal of Materials Processing Technology[J], 2011, 211: 1729

9 Zhang S L, Zhao Y T, Cheng X N et al. Journal of Alloys and Compounds[J], 2009, 470: 168

10 Patel B, Chaudhari G P, Bhingole P P. Materials Letters[J], 2012, 66: 335

11 Ai X L, Yang J, Quan G F. Foundry[J], 2009, 58: 482 (in Chinese)
12 Qian M, Ramirez A, Das A. Journal of Crystal Growth [J], 2009, 311: 3708

13 Pan J, Yoshida M, Sasaki G et al. Materials and Manufacturing Processes[J], 2000, 15: 867

14 Liu Q M. Research of Ultrasonic Treatment on Solidification Characteristics and Structure of Metals[M]. Shanghai: Shanghai University Press, 2007: 22 (in Chinese)

15 Ramirez A, Qian M, Davis B et al. Scripta Materialia [J], 2008, 59: 19

\title{
超声对 AZ80 镁合金显微组织演化及力学性能的影响
}

\author{
薛寒松 ${ }^{1,2}$, 李 迪 ${ }^{1}$, 杨 刚 $^{1}$, 张丁非 ${ }^{1,2}$ \\ (1. 重庆大学材料科学与工程学院, 重庆 400044) \\ (2. 国家镁合金材料工程技术研究中心，重庆 400044)
}

摘 要: 研究超声处理对AZ80镁合金微观结构演化及力学性能的影响。研究表明, 经超声处理后, 初生 $\alpha-\mathrm{Mg}$ 相由粗大的树枝晶变为细 小的球状等轴晶, 且 $\beta-\mathrm{Mg}_{17} \mathrm{Al}_{12}$ 相明显细化, 由连续网状分布变成不连续分布。此外, 合金经超声处理后, 力学性能得到明显提高, 屈 服强度、抗拉强度和伸长率分别由 $87 \mathrm{MPa}, 118 \mathrm{MPa}$ 和 $2.1 \%$ 提高到 $107 \mathrm{MPa} 、 170 \mathrm{MPa}$ 和 $5.4 \%$ 。

关键词: AZ80 镁合金; 超声处理; 微观结构; 力学性能

作者简介: 薛寒松, 男, 1968 年生, 博士, 副教授, 重庆大学材料科学与工程学院, 重庆 400044, 电话: 023-65111212, E-mail: hsxue@sohu.com 